\title{
Doença de Parkinson: mapeamento da produção científica e tecnológica desenvolvida no mundo
}

\author{
Parkinson's disease: mapping \\ of scientific and technological \\ production developed in the world
}

\section{Bianca de Láia Vicentini}

ORCID: https://orcid.org/0000-0003-2131-7798

Graduanda em Biblioteconomia e Gestão de

Unidades de Informação- Universidade Federal do

Rio de Janeiro (UFRJ).

e-mail: bianca.vicentini@icict.fiocruz.br

\section{Rejane Ramos Machado}

ORCID: https://orcid.org/0000-0003-4645-1774

Doutora em Ciências pelo Programa de Pós-

Graduação em Informação e Comunicação em Saúde

(PPGICS) da Fundação Oswaldo Cruz (Fiocruz).

e-mail: rejane.machado@icict.fiocruz.br

\section{Lana Grasiela Alves Marques}

ORCID: https://orcid.org/0000-0003-1362-5299

Pós-Doutorado nas áreas de Bioprospecção e

Propriedade Intelectual- Universidade Federal do

Ceará (UFC). Doutora em Biotecnologia-

Universidade Federal do Ceará (UFC).

e-mail: lanagrasiela@gmail.com 
RESUMO: A Doença de Parkinson é a segunda doença neurodegenerativa mais prevalente no mundo, portanto, entendendo a relevância das produções sobre a doença, o presente trabalho apresenta os resultados da realização do levantamento da produção científica e tecnológica desenvolvida no Brasil e no mundo referentes à Doença de Parkinson, utilizando os softwares Vantage Point e Excel da Microsoft Office para limpeza dos dados e tratamento bibliométrico. Observou-se que os Estados Unidos são líderes mundiais tanto nos rankings de artigos científicos quanto em tecnologias patenteadas. Ademais, o Brasil possui uma quantidade considerável de produções, apesar de suas lacunas se comparado mundialmente, principalmente em relação ao número de patentes.

PALAVRAS-CHAVE: Doença de Parkinson; artigos; patentes.

ABSTRACT: Parkinson's disease is the second most prevalent neurodegenerative disease in the world; therefore, understanding the relevance of the productions on the disease, this paper presents the results of the survey of scientific and technological production developed in Brazil and in the world related to Parkinson's disease, using Microsoft Office's Vantage Point and Excel software for data cleaning and bibliometric treatment. It was observed that the United States is a world leader both in the rankings of scientific articles and in patented technologies. Furthermore, Brazil has a considerable amount of production, despite its gaps when compared worldwide, mainly in relation to the number of patents.

KEYWORDS: Parkinson disease; articles; patents.

\section{Introdução}

Em quase todo o mundo, o contingente que mais cresce é o de pessoas com idade igual ou superior a 60 anos. Segundo a Organização Mundial da Saúde (OMS) 754,6 milhões de indivíduos estavam nessa faixa etária em 2010. As projeções apontam para 1,4 bilhão em 2030, podendo chegar aos dois bilhões em 2050 (WHO, 2020).

Ainda de acordo com os cálculos da OMS, 1\% das pessoas com mais de 65 anos será afetado pela Doença de Parkinson (DP) (FERNANDES; ANDRADE FILHO, 2018). Sendo uma doença degenerativa e progressiva do sistema nervoso 
central, o Parkinsonismo é reconhecido pela morte neuronal na substância negra; por consequência disso, ocorre a diminuição de dopamina, resultando em modificações motoras (GOULART et al., 2004).

A DP é estabelecida como uma grande categoria de doenças que demonstram redução da neurotransmissão dopaminérgica nos gânglios da base, categorizando-se em: parkinsonismo primário, secundário, plus e heredodegenerativas (SOUZA et al., 2011). Não havendo motivos específicos para ser manifesto considera-se, entretanto, que a apresentação de sintomas do Parkinson pode ser causada por fatores ambientais e genéticos, sendo possível favorecer para a evolução neurodegenerativa da doença. Trata-se de uma patologia crônica e progressiva do sistema nervoso, distinguida pelos sinais cardinais de rigidez, acinesia, bradicinesia, tremor e instabilidade postural (SOUZA et al., 2011).

Segmentando em 6 estágios o impacto do Parkinson nas regiões cerebrais afetadas, afirma-se sobre seu desenvolvimento que:

No estágio 1 ocorre o comprometimento do núcleo motor dorsal dos nervos glossofaríngeo e vago, além da zona reticular intermediária e do núcleo olfatório anterior, constituindo assim um processo neurodegenerativo quase que totalmente localizado nas fibras dopaminérgicas que inervam o putâmen dorso-lateral. No estágio 2, existe o comprometimento adicional dos núcleos da rafe, núcleo reticular gigantocelular e do complexo do lócus cerúleos. No estágio 3, observa-se o acometimento da parte compacta da substância negra do mesencéfalo. Já nos estágios 4 e 5 há comprometimentos das regiões prosencefálicas, do mesocórtex temporal e de áreas de associação do neocórtex e neocórtex pré-frontal, respectivamente. No estágio 6, ocorre o comprometimento de áreas de associação do neocórtex, áreas pré-motoras e área motora primária (SOUZA et al., 2011, p. 720).

Em razão de diversos motivos, dentre eles o condicionamento físico escasso e oscilações de equilíbrio, o avanço da idade pode modificar as condições de saúde de muitos indivíduos, limitando-os em suas atividades cotidianas. Todavia, em muitos casos, a situação pode ser amenizada ou até transformada por meio da 
prática de exercícios constantes (GOULART et al., 2004). A qualidade de vida é prejudicada pelas impossibilidades motoras que dificultam as interações sociais dos indivíduos, comprometendo seus objetivos e perspectivas. Portanto, esse é um dos fatores mais complexos a serem enfrentados pelos portadores da DP, justamente pelo acometimento físico que causa danos à qualidade de vida (SILVA et al., 2010).

O presente trabalho teve como objetivo realizar o levantamento da produção científica e tecnológica desenvolvida no Brasil e no mundo, referente à DP, analisando a evolução cronológica do número de artigos científicos e patentes, identificando os países e instituições que apresentam o maior número de produções, assim como os principais titulares e inventores das tecnologias patenteadas.

\section{Metodologia}

A metodologia utilizada para a prospecção científica e tecnológica foi a coleta e a análise dos artigos científicos e das patentes. A pesquisa dos artigos foi realizada nas bases Web of Science (WoS), Scopus e PubMed. Para as patentes a busca foi feita nas bases de dados Espacenet do European Patent Office (EPO), Derwent Innovations Index (DII), Lens.org e a ferramenta Orbit Intelligence. A estratégia utilizada foi a busca pelas palavras-chave "Parkinson disease" e "Parkinson and disease", aplicando o uso das aspas duplas para recuperar o termo exato, sem variações, sendo a última usada somente na ferramenta Orbit Intelligence e na base Espacenet. É importante ressaltar que a definição metodológica das palavras-chave varia de acordo com cada base de dados para o alcance de melhores resultados.

A pesquisa realizada na base de dados PubMed, através da ferramenta $\mathrm{Ad}$ vanced Search Builder, foi estruturada com o refinamento Title/Abstract para que o termo fosse recuperado nesses campos, alcançando assim maior precisão sobre o assunto abordado pelo artigo científico. Na WoS, utilizou-se o campo Topic, além de ter sido usado o refinamento Article, e na base Scopus, foi utilizado no campo Simple search o refinamento Article para o tipo de documento e Abstract para en- 
contrar o termo nesse campo.

No DII a palavra-chave foi pesquisada no campo Topic, sendo sua estrutura de busca a mesma da WoS, já para o Orbit Intelligence, foi utilizado o refinamento Abstract no campo Advanced search para o alcance dos resultados. Ademais, também foi realizada a busca no Espacenet, usando o campo Advanced search e o refinamento Title or Abstract. Por fim, na base Lens.org a busca foi feita no campo Title, Abstract, Claims.

Para a limpeza dos dados e o tratamento bibliométrico foram utilizados os softwares Vantage Point - usando a função Clean-up - e o Excel da Microsoft Office, além de recursos oferecidos pelas próprias bases. A pesquisa foi realizada em janeiro de 2020.

\section{Resultados e discussão}

O número de artigos científicos recuperados utilizando a palavra-chave definida na metodologia consta na Tabela 1:

Tabela 1 - Numeros de artigos recuperados
\begin{tabular}{llll}
\hline Palavras-chave & WoS & PubMed & Scopus \\
Base de dados & & & \\
\hline "Parkinson disease" & 9.120 & 11.400 & 66.457 \\
\hline
\end{tabular}

Fonte: Autoria própria (2020)

A Tabela 2 aponta o número de documentos de patentes recuperados utilizando as palavras-chave definidas na metodologia. 


\begin{tabular}{|c|c|c|c|c|}
\hline Palavras-chave & DII & Espacenet & Orbit & Lens \\
\hline \multicolumn{5}{|c|}{ Base de dados } \\
\hline "Parkinson disease" & 1.215 & & & 25.858 \\
\hline "Parkinson and disease" & & 6.554 & 6.815 & \\
\hline
\end{tabular}

A evolução anual dos 9120 documentos analisados nas bases de dados de artigos científicos está demonstrada na Figura 1. Essa Figura aponta, segundo os registros da WoS, que o ano de 1955 possui um artigo científico sobre a DP. De autoria de ELIASBERG, W. G., com o título da publicação ANGIOSPASTIC STATES AND PARKINSON DISEASE, publicado pelo AMERICAN JOURNAL OF PSYCHIA$T R Y$, na área de pesquisa de psiquiatria. Ele trata sobre quais são os possíveis usos do teste bimotor, como: diagnóstico e diagnóstico diferencial de doença cerebral; entendimento da psicologia da convalescença ou alterações psicológicas no percurso do Parkinsonismo; e a análise do retorno ao tratamento através das manifestações físicas e mentais (ELIASBERG, 1955).

Observa-se também que, de 1991 em diante, o número de publicações começou a crescer, entretanto, só ocorreu uma evolução considerável a partir do ano de 2001 com 87 artigos, chegando a 725 em 2017 e depois caindo para 589 em 2019. 
Figura 1 - Numeros de artigos publicados e patentes depositadas por ano no mundo.

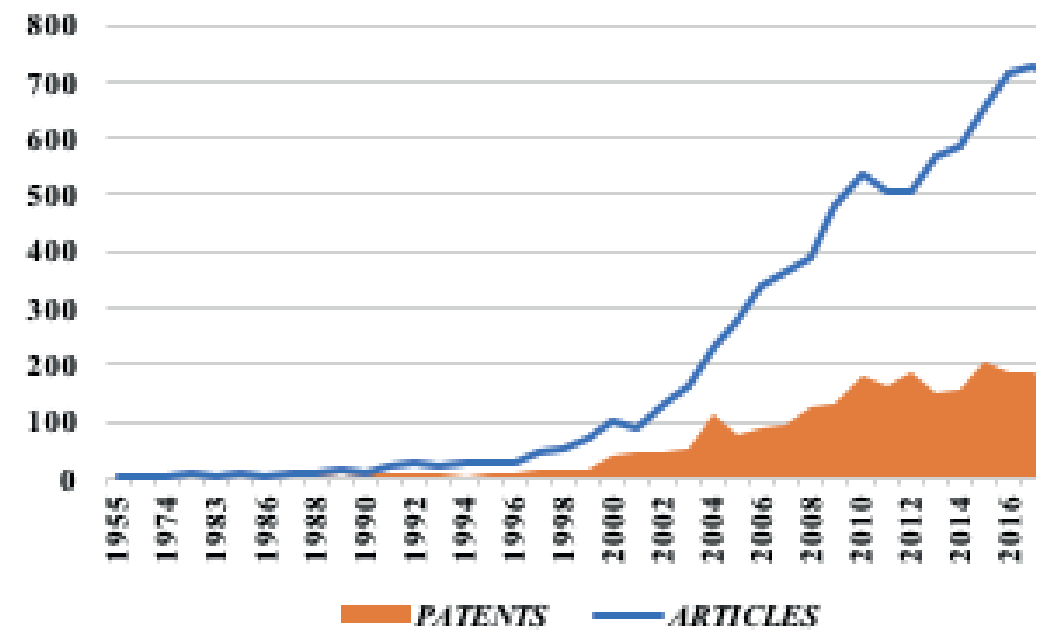

Fonte: Autoria própria (2020)

Os dados referentes às patentes apontam que as primeiras patentes foram depositadas no ano de 1959. Uma delas tem como título TROPINE ESTER, e seus inventores são Flockhart, Robert Goodman Johnston, Robert Per Paton, e Muriel Elizabeth Farquharson. A invenção é referente a um novo éster de tropina, seus sais de adição de ácido não tóxicos e a preparação destes compostos. De acordo com a invenção, é fornecido o éster do ácido 1 -fenilciclohexanocarboxílico da tropina e seus sais de adição de ácido não tóxico. Esse éster tem a fórmula: $\mathrm{CH}-\mathrm{CH}-\mathrm{CH} 2$ I 6 ocoo CH NECH 3 CM 2 CH 2 CR 2-C -CH 2 CI I CH 2 CH 2 CR 2. O método da invenção envolve o aquecimento conjunto, em um solvente assim como xileno, um alquil inferior, de preferência metil, éster de 1 ácido fenil ciclohexanocarboxílico e tropina no acompanhamento de um catalisador de transesterificação - sendo este o sódio. O álcool produzido no decurso da transesterificação é destilado até que a reação se encontre em estado completo, e a partir da mistura de reação o éster bruto seja isolado. É apropriado transformar o éster bruto em seu cloridrato e absterger o cloridrato b recristalização. A base livre pode então ser alcançada 
por meio do cloridrato de todas as formas convenientes conhecidas em si mesma (FLOCKHART et al., 1959).

Foram apontados por resultados em animais que o éster do ácido 1-feniciclohexanocarboxílico da tropina, no formato de seus sais de adição de ácido não tóxico, nitidamente o cloridrato, tinha especificidades farmacológicas que mostravam a possibilidade de ser útil no tratamento de Parkinson. Nos ensaios clínicos em humanos houve a comprovação, pois diminui o tremor e a rigidez em portadores da doença, quando a substância é aplicada oralmente em doses de 10 miligramas três vezes ao dia. (FLOCKHART et al., 1959).

A outra patente, BASIC-SUBSTITUTED ESTERS OF HYDRACLYLIC ACID, que tem como titular a empresa química e farmacêutica alemã Bayer, diz respeito a novos ésteres básicos substituídos de ácido hidracrílico e, notadamente, a ésteres básicos substituídos de ácido hidracrílico SS-substituído, e à formação destes. Desse modo, foi constatado que estes novos compostos integram combinações terapeuticamente utilizáveis que são, sobretudo, competentes no tratamento da DP (BAYER, 1959).

Fundada em 1863 por Friedrich Bayer e Johann Weskott, a Bayer é uma organização global com competências centrais nas áreas de saúde e agricultura, e completou em 2018 a maior aquisição de sua história, passando a ser líder em agricultura (BAYER S.A., 2019).

As informações a seguir sobre os países e organizações, instituições e titulares que possuem o maior número de artigos e patentes com relação ao Parkinson são referentes aos dados recuperados das bases WoS e DII.

No ranking dos 15 primeiros países e organizações com maior número de publicações em artigos científicos estão presentes: Estados Unidos, na liderança, com 3.927 publicações, seguido de Itália (732) e Alemanha (719); ademais Reino Unido (648), Canadá (630), China (597), França (556), Japão (490), Espanha (445), Coréia (330), Países Baixos (285), Austrália (256), Suécia (231), Brasil (226) e Suíça (182). O Brasil, com 226 artigos científicos, teve seu maior número de publicações 
em 2017 (32), e os primeiros artigos foram publicados em 2001. Um deles tem como título EFFECTS OF AGE ON ELEMENTS OF INSULIN-SIGNALING PATHWAY IN CENTRAL NERVOUS SYSTEM OF RATS, realizado pela Universidade de Campinas (Unicamp) e a Universidade Federal do Rio de Janeiro (UFRJ), nas áreas de Endocrinologia e Metabolismo pela revista Endocrine; aborda o tema dos idosos, que, além terem inclinação à resistência de insulina e, por conseguinte, ao diabetes tipo 2, apresentam doenças do sistema nervoso central que podem ser motivadas por distúrbios da sinalização de insulina no cérebro, como comprometimento da memória, e doenças de Alzheimer e Parkinson. Então, foram examinadas as manifestações e respostas à insulina de elementos envolvidos na via de sinalização de insulina no córtex do prosencéfalo e cerebelo de ratos, com idades de uma a 60 semanas (FERNANDES; SAAD; VELLOSO, 2001).

Segundo as informações de seu site oficial, a Unicamp produziu $8 \%$ da pesquisa acadêmica nacional, $12 \%$ da pós-graduação e com relação ao número de patentes artigos científicos per capita publicados anualmente em revistas indexadas na base de dados WoS, continua na liderança entre as universidades. Além disso, lidera o ranking nacional per capita de publicações científicas nas revistas internacionais catalogadas (UNICAMP, 2019).

A UFRJ é a primeira universidade brasileira criada pelo Governo Federal, em 1920, porém em atividade desde 1792, com a Escola Politécnica (UFRJ, 2020). É a maior universidade federal do país, e foi considerada a quarta instituição com o maior número de produções científicas no Brasil entre 2014 e 2018. Encontra-se em primeiro lugar no estado do Rio de Janeiro. A pesquisa foi solicitada pela Universidade de São Paulo (USP), sendo realizada pela Clarivate Analytics por meio da base de dados WoS. Também é apresentado que a UFRJ produziu 14.056 trabalhos científicos no período, levando em conta somente artigos e revisões. Segundo os resultados, 6,56\% da ciência desenvolvida no País é produzida pela universidade (UFRJ, 2019).

Outro artigo do Brasil publicado em 2001, INTER-LABORATORY COMPARI- 
SON OF DNA PRESERVATION IN ARCHIVAL PARAFFIN-EMBEDDED HUMAN BRAIN TISSUE FROM PARTICIPATING CENTRES ON FOUR CONTINENTS, realizado em colaboração entre os países Argentina, Austrália, Brasil, Alemanha, Estados Unidos, Japão, e Reino Unido, na área de Genética e Hereditariedade, Neurociências e Neurologia, visa esclarecer o papel da variação da sequência do Ácido Desoxirribonucleico (DNA) mitocondrial em doenças neurodegenerativas humanas usando DNA de várias origens étnicas, por isso foram apurados os elementos que induzem a preservação do DNA de arquivo e sua adequação à Proteína C-reativa (PCR). Além disso, realizou-se uma verificação das amostras de tecido neuropatológico que foram processadas em 18 centros internacionais em 4 continentes distintos. (KOSEL et al., 2001).

Analisando os resultados sobre as patentes identifica-se que os Estados Unidos, assim como nos artigos sobre Parkinson, ocupam o primeiro lugar com 525 patentes, seguidos da China com 289, que referente aos artigos científicos está na sexta posição, porém, com menor número de patentes do que de artigos (597) de acordo com a base. O Canadá se encontra em terceiro lugar, com 160. Além disso, durante a limpeza dos dados foram retirados da Organização Mundial da Propriedade Intelectual os depósitos realizados pelos Estados Unidos, China, Canadá, Escritório Europeu de Patentes, Coréia e Japão, atribuindo-os aos seus respectivos países.

O Brasil está em décimo primeiro lugar, com 25 patentes depositadas, tendo um número muito maior de artigos científicos (226). Em 2006, o Brasil teve sua primeira patente depositada referente à Doença de Parkinson, tendo como título METHOD FOR IMMUNAGGLUTINATION OF MICRON AND NANOSPHERES OF POLYSTYRENE, INVOLVES ACTIVATION OF MICRON AND NANOSPHERES WITH DIFFERENT CHEMICAL AND SENSITIZED GROUPS OF FILAMENTOUS BACTERIOPHAGES, sendo seus inventores GOULART, L. R., PERES, FRESCHI A. P., MADURRO, M. J., CARDOSO, R., CAPPARELLI, F. E., ALMEIDA, J. F., RISPOLI, R. G., PRUDENCIO, C. R., LINO DE SOUZA G. R., e seus titulares a empresa 
Imunoscan Engenharia Molecular LTDA, e a Universidade Federal de Uberlândia. A patente aplica um método que é utilizado para imunoaglutinação de mícrons e nanoesferas de poliestireno, e demonstra a vantagem de assegurar a detecção com brevidade, precisão, sensibilidade e reprodutibilidade, usando pequenas quantidades de amostras e reagentes, oportunizando conveniência e baixo custo. As doenças incluídas para tratamento pela invenção são: tétano, tuberculose, hanseníase, meningite, dengue, síndrome da imunodeficiência adquirida, hepatite, toxoplasmose, leishmaniose, malária, vários tipos de câncer, doenças de Alzheimer e Parkinson, fibrose cística, hipercolesterolemia e anemia e esclerose múltipla (GOULART et al., 2006).

A empresa Imunoscan Engenharia Molecular LTDA encontra-se localizada em Uberlândia, Minas Gerais, realiza atividades de pesquisa e desenvolvimento no âmbito das ciências da vida, tais como: medicina, biologia, bioquímica, farmácia, agronomia e conexas. Além de produzir também nas áreas das ciências físicas e de engenharia, como: matemática, física, astronomia, química, geociências e similares (CNPJ, 2018).

De acordo com um levantamento realizado pela Clarivate Analytics com dados WoS, a Universidade Federal de Uberlândia (UFU) ocupa a quarta posição no ranking das instituições com o maior número de produções científicas em Minas Gerais, tendo como base o período de 2014 a 2018. Na colocação nacional, a universidade ficou em $28^{\circ}$ lugar entre 50 instituições. A instituição produziu 3.345 trabalhos científicos, que representam 1,56\% das pesquisas desenvolvidas no Brasil, ao longo de 5 anos, e, em 2018, a UFU e mais 35 universidades brasileiras entraram no maior ranking educacional do mundo. A universidade ficou entre as 1.100 melhores do mundo (UFU..., 2019).

Com base nos dados recolhidos e analisados, a instituição com maior número de artigos científicos publicados é a Universidade de Washington, com 355 publicações, seguida da Universidade de Harvard com 295, e pela Clínica Mayo com 264. A primeira publicação entre as 10 primeiras instituições do ranking foi no ano de 
1978, pela Universidade da Pensilvânia. Além disso, os anos com maior número de publicações pelas instituições foram 2017 e 2016 em primeiro e segundo lugar respectivamente. Um crescimento significativo e com certa constância inicia-se a partir de 2010.

Ocupando o primeiro lugar no ranking, a Universidade de Washington (UW) é uma das universidades públicas mais importantes do mundo (UW, 2020). Listada no $5^{\circ}$ lugar entre as 100 universidades mais inovadoras do mundo, agora, em seu quinto ano, a classificação aborda as instituições de ensino que contribuem da maior maneira para o progresso da ciência e tecnologia, também colaborando para o avanço econômico mundial. Pelo terceiro ano ininterrupto, a UW permanece como a instituição pública dos EUA mais bem posicionada na lista (HOLTZ, 2019).

Com relação às patentes, segundo os dados do DII, a empresa Medtronic INC ocupa o primeiro lugar, com 24 patentes, logo após, em segundo, está a Merck Canadá LTD com 17 e a Sanofi SA com 15 patentes, em terceiro lugar.

A Medtronic INC está presente em 160 países, e foi fundada em 1949 como uma loja de equipamentos médicos por Earl Bakken e Palmer Hermundslie. Ao longo dos anos a empresa desenvolveu tecnologias centrais adicionais, incluindo equipamentos mecânicos implantáveis, de administração de medicamentos e biológicos, além de instrumentos cirúrgicos de energia avançados e elétricos. Hoje, suas tecnologias são usadas para tratar quase 40 condições médicas (MEDTRONIC, 2020).

A empresa Merck Canadá LTD, que ocupa o segundo lugar, tem como organização mãe a Merck Sharp \& Dohme. Nos Estados Unidos e no Canadá é conhecida como Merck, sendo Merck \& Co., INC. seu nome legal. Trata-se de uma empresa global dedicada aos cuidados com a saúde e com mais de 325 anos de história, sua sede fica em Kenilworth, New Jersey, EUA, atuando em mais de 140 países. As principais áreas de atuação da empresa são em oncologia, vacinas, diabetes, doenças infecciosas, e saúde animal (MERCK \& CO. INC, 2018).

Outra questão interessante é o fato de haver muito mais patentes depositadas 
por empresas do que por universidades. De acordo com os resultados obtidos, há apenas uma universidade entre os 10 primeiros titulares, sendo a Universidade de Yonsei na Coreia do Sul, a que ocupa o oitavo lugar com 13 patentes.

\section{Conclusão}

A partir dos resultados obtidos, foi possível observar que os artigos científicos referentes à Doença de Parkinson tiveram início por volta de 1955, um pouco antes das patentes (em 1959). Ainda foi possível analisar que os Estados Unidos são líderes mundiais no número de artigos publicados e patentes depositadas, seguidos da China com relação às patentes, que possui grande avanço, e da Itália no que se refere aos artigos científicos. Por conseguinte, as principais instituições e organizações presentes nos rankings mundiais de produção científica e tecnológica sobre Parkinson são estadunidenses.

Além disso, considerando toda a complexidade para desenvolver pesquisa e tecnologia na área de doenças neurodegenerativas, também entendendo o período de começo das produções e suas evoluções ao longo do tempo, o Brasil apresenta lacunas com relação às suas produções, tendo suas primeiras publicações de artigos em 2001, e sua primeira patente depositada em 2006.

Por fim, a necessidade e relevância do desenvolvimento de novas produções que ajudem mais a conhecer, tratar e prevenir o Parkinson é indubitável, sendo essa a segunda doença neurodegenerativa mais prevalente no mundo.

\section{Agradecimentos}

\section{$\mathrm{CNPq}$}

\section{Referências:}

BAYER. Basic-substituted esters of hydraclylic acid. Titular: Bayer S.A. GB873430. Depósito: 1959.

BAYER S.A. Bayer Brasil, 2019. Diário Oficial Empresarial Bayer S.A. Disponível em: https://www.bayer.com. br/static/documents/pdf/balanco-financeiro-bayer-2018.pdf. Acesso em: 28 fev. 2020. 
CNPJ. CNPJ.BIZ, 2018. Disponível em: https://cnpj.biz/06935380000132. Acesso em: 28 mar. 2020.

ELIASBERG, W. G. Angiospastic states and Parkinson disease. American journal of psychiatry. v.111, ed.11, p. 851-844, 1955. Disponível em: https://ajp.psychiatryonline.org/doi/10.1176/ajp.111.11.841. Acesso em: 23 jan. 2020.

FERNANDES, I.; ANDRADE FILHO, A. S. Estudo clínico-epidemiológico de pacientes com Doença de Parkinson em Salvador-Bahia. Revista Brasileira de Neurologia e Psiquiatria, p. 45-59, jan. /abr. 2018. Disponível em: https://www.revneuropsiq.com.br/rbnp/article/view/244/141. Acesso em: 25 jan. 2020.

FERNANDES, M. L.; SAAD, M. J.; VELLOSO, L. A. Effects of age on elements of insulin-signaling pathway in central nervous system of rats. Endocrine. p. 227-234, 2001. Disponível em: https://pubmed.ncbi.nlm.nih. gov/11954667/. Acesso em: 23 jan. 2020.

FLOCKHART; JOHNSTON, R. G.; PATON, R. P.; FARQUHARSON, M. E. Tropine ester. Titular: Duncan, Flockhart \& Co. LTD. GB870301. Depósito: 9 abr. 1959. Disponível em: https://worldwide.espacenet.com/patent/search/ family/009995504/publication/GB870301A?q=pn\%3DGB870301A. Acesso em: 08 fev. 2020.

GOULART, F.; SANTOS, C. C.; TEIXEIRA-SALMELA, L. F.; CARDOSO, F. Análise do desempenho funcional em pacientes portadores de doença de Parkinson. Acta Fisiátrica, p.12-16, 2004. Disponível em: https://www. revistas.usp.br/actafisiatrica/article/view/102466. Acesso em: 10 fev. 2020.

GOULART, L. R. et al. Method for immunagglutination of micron and nanospheres of polystyrene, involves activation of micron and nanospheres with different chemical and sensitized groups of filamentous bacteriophages. Titular: Imunoscan Engenharia Molecular LTDA; Universidade Federal de Uberlândia. BR200603590-A2. Depósito: 2006.

HOLTZ, Jackson. UW is most innovative U.S. public university; № 5 in the world, according to Reuters. UW News, 2019. Disponível em: https://www.washington.edu/news/2019/10/23/uw-is-most-innovative-u-s-public-university-no-5-in-the-world-according-to-reuters/. Acesso em: 29 fev. 2020.

KOSEL, S. et al. Inter-laboratory comparison of DNA preservation in archival paraffin-embedded human brain tissue from participating centers on four continents. Neurogenetics. ed.3, p.163-170, 2001. Disponível em: https://pubmed.ncbi.nlm.nih.gov/11523568/. Acesso em: 12 fev. 2020.

MEDTRONIC. Medtronic, c2020. Company history. Disponível em: https://www.medtronic.com/br-pt/about/ history.html. Acesso em: 14 mar. 2020.

MERCK \& Co. INC. Merck inventing for life, 2018. About us. Disponível em: https://www.merck.com/about/ home.html. Acesso em: 14 mar. 2020.

SILVA, F. S.; PABIS, J.V. C.; ALENCAR, A. G.; SILVA, K. B.; NAVARRO-PETERNELLA, F. M. Evolução da doença de Parkinson e comprometimento da qualidade de vida. Revista Neurociência, 2010, p. 463-468. Disponível em: http://www.revistaneurociencias.com.br/edicoes/2010/RN1804/501\%20original.pdf. Acesso em: 12 fev. 2020

SOUZA, C. F. M.; ALMEIDA, H. C. P.; SOUSA, J. B.; COSTA, P. H.; SILVEIRA, Y. S. S.; BEZERRA, J. C. L. A doença de Parkinson e o processo de envelhecimento motor: uma revisão de literatura. Revista Neurociência, 2011, p.718 -723. Disponível em: http://revistaneurociencias.com.br/edicoes/2011/RN1904/revisao\%2019\%20 04/570\%20revisao.pdf /. Acesso em: 14 fev. 2020.

UFRJ. UFRJ fica em $4^{\circ}$ lugar em ranking nacional de produção científica. Conexão UFRJ, 2019. Disponível em: https://conexao.ufrj.br/2019/04/17/ufrj-fica-em-4o-lugar-em-ranking-nacional-de-producao-cientifica/. Acesso em: 27 fev. 2020.

UFRJ. Universidade Federal do Rio de Janeiro, c2020. História. Disponível em: https://ufrj.br/historia. Acesso 
em: 27 fev. 2020

UFU é a $4^{a}$ em produção de pesquisas no Estado. Diário de Uberlândia, 2019. Disponível em: https:// diariodeuberlandia.com.br/noticia/20854/ufu-e-a-4--em-producao-de-pesquisas-no-estado. Acesso em: 29 fev. 2020.

UNICAMP. Unicamp, 2019. A universidade. Disponível em: https://www.unicamp.br/unicamp/universidade. Acesso em: 26 fev. 2020.

UW. University of Washington, c2020. Discover the University of Washington. Disponível em: https://www. washington.edu/about/?utm_source=whitebar\&utm_medium=click\&utm_campaign=about\&utm_term=abouttheuw. Acesso em: 29 fev. 2020.

WHO. World Health Organization, c2020. Ageing. Disponível em: https://www.who.int/health-topics/ ageing\#tab=tab_1. Acesso em: 10 fev. 2020. 